\title{
CALL FOR PAPERS: RESEARCH ON LEARNING AND TEACHING PROBABILITY WITHIN STATISTICS
}

The Statistics Education Research Journal (SERJ), a journal of the International Association for Statistical Education (IASE), is planning a special issue for November 2016, focused on the topic of Research on Learning and Teaching Probability within Statistics. Deadlines: Expressions of intent by December 19, 2014 and full papers by June 1, 2015. The Guest Editors for this special edition will consist of members of the Topic 6 group at the recent ICOTS 9: Egan Chernoff (egan.chernoff@usask.ca), Efi Paparistodemou (e.papristodemou@cytanet.com.cy), Dionysia Bakogianni (dbakogianni@math.uoa.gr) and coeditor of SERJ Special Editions Peter Petocz (peter.petocz@mq.edu.au).

\section{BACKGROUND}

SERJ has had a number of special editions in its previous volumes: research on reasoning about variability (vol. 3, no. 2, 2004), reasoning about distribution (vol. 5, no. 2, 2006), informal inference (vol. 7, no. 2, 2008), qualitative approaches in statistics education research (vol. 9, no. 2, 2010), attitudes towards statistics (vol. 11, no. 2, 2012), and a global view of statistics education research (vol. 13, no. 2, 2014). The special issue Research on Learning and Teaching Probability within Statistics will continue the tradition of focusing one issue every two years on a specific and current problem in statistics education research.

The core of this special edition will be based on relevant papers presented at the ICOTS 9 conference in Flagstaff, July 2014. At that conference, invited papers were limited to six pages (and contributed papers to four pages). The editors will invite authors of relevant papers to prepare versions of their research on learning and teaching probability within statistics that are more extensive and/or further developed. Researchers who did not present papers at ICOTS 9 on this topic are also invited to submit an expression of intent, and a subsequent paper. All submissions will go through the usual SERJ double-blind refereeing process.

The description of Topic 6 at ICOTS 9 will provide a general guideline for the focus of the special issue. Here is the (slightly modified) description:

"Concepts and models of uncertainty and variability are at the heart of statistical thinking and analysis. Hence, probabilistic concepts and thinking underpin all of statistics. Chance and data developments should be intertwined, in harmony, and driven by data, real contexts and problem-solving. As in all of statistics, students bring concepts and intuitions from everyday real experiences to formal education in probability. The teaching of probability needs to build on these and to link formal notions to the everyday, to real contexts and constantly - to data. In order to enrich conceptual understanding and underpin formal developments with experiential insights, sustainable representations of probability, integrated with data and statistical thinking, will render concepts accessible and more easily exemplified. These sessions will address much-needed reforms in teaching probability in harmony with statistics, and will explore current innovations and new directions."

\section{POSSIBLE TOPICS}

Examples of topics that may be relevant for this special issue on Research on Learning and Teaching Probability within Statistics include, but are not limited to:

a. Articles that report on research about learning probability in the context of statistics courses at any level, from primary schooling to tertiary education.

b. Articles that report on research about teaching probability in the context of statistics courses at any level, from primary schooling to tertiary education.

Statistics Education Research Journal, 13(2), 11-12, http://iase-web.org/Publications.php?p=SERJ C International Association for Statistical Education (IASE/ISI), November, 2014 
c. Articles that investigate the teaching and learning of particular aspects of probability, such as Bayesian approaches, or the use of $p$-values in inference.

d. Articles that investigate the teaching and learning of probability with specific groups of people, such as future teachers of statistics.

e. Reviews of current research on learning and teaching probability within statistics.

f. Frameworks/models for learning and teaching probability within statistics.

\section{SUBMISSION GUIDELINES}

Manuscripts for this special issue will be limited to a maximum of 7500 words of body text and authors are encouraged to aim for 4000-6000 words of body text (not counting abstract, tables and graphs, references, appendices). Note particularly that manuscripts can be written in Spanish, French, or English; those in Spanish or French will be published with an English summary of around 1000 words (see the papers by Mayén et al. in vol. 8, no. 2, and by BihanPoudec in vol. 9, no. 2). Manuscripts should be submitted in accordance with SERJ's standard Author Guidelines and using the Template file found on the Journal's website: http://iaseweb.org/Publications.php? $\mathrm{p}=$ SERJ

\section{DEADLINES AND CONTACT INFORMATION}

Interested authors should send a letter of intent by December 19, 2014, but preferably earlier, consisting of a 150-250 word abstract describing key aspects of the research. This letter should be sent by e-mail to any of the SERJ guest editors for this special issue: Egan Chernoff (egan.chernoff@usask.ca), Efi Paparistodemou (e.papristodemou@cytanet.com.cy), Dionysia Bakogianni (dbakogianni@math.uoa.gr), or to SERJ co-editor Peter Petocz (Peter.Petocz@mq.edu.au). Authors will be sent an acknowledgement of their letter, and can expect to receive a response from the editorial team within three weeks. Potential authors with informal queries regarding the suitability of a planned paper are also encouraged to contact any member of the team.

Full manuscripts must be submitted by June 1, 2015 at the latest to any member of the editorial team, in accordance with the submission guidelines listed earlier. Again, authors will be sent an acknowledgement of the manuscript's receipt. Decisions about the suitability of proposed papers and the allocation of accepted papers to the special issue (or alternatively to a regular $S E R J$ issue) will be made jointly by the Guest Editors and the SERJ co-Editors. 